\title{
Validation of a HPLC Method for Determination of Glutamine in Food Additives Using Post-Column Derivatization
}

\author{
Marlus Chorilli ${ }^{1}$, Hérida Regina Nunes Salgado ${ }^{1}$, Fabiana De Santana Santos ${ }^{2}$, \\ Lucélia Magalhães Da Silva ${ }^{3^{*}}$ \\ ${ }^{1}$ Departamento de Fármacos e Medicamentos, Faculdade de Ciências Farmacêuticas de Araraquara, \\ Universidade Estadual Paulista (UNESP), Araraquara, Brazil \\ ${ }^{2}$ Faculdade de Americana, Americana, Brazil \\ ${ }^{3}$ Programa de Pós-Graduação em Ciências Farmacêuticas, Faculdade de Ciências Farmacêuticas \\ de Araraquara, Universidade Estadual Paulista (UNESP), Araraquara, Brazil \\ Email: *lucmsil@yahoo.com.br
}

Received November 1, 2011; revised December 4, 2011; accepted December 15, 2011

\begin{abstract}
An ion-exchange chromatography (IEC) followed by post-column derivatization method was validated for the determination of glutamine in food additive products. The chromatographic method was carried out on a sodium

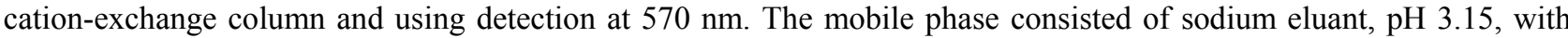
$5 \%$ sulfolane, sodium eluant, $\mathrm{pH} 7.40$ and sodium column regenerant. The method was linear in the range of $4-50$ $\mu \mathrm{g} / \mathrm{mL}\left(r^{2}=0.9999\right)$. The accuracy was $99.78 \%$. Moreover, method validation demonstrated acceptable results for precision and robustness. The method was found to be able to use for routine analysis of the glutamine.
\end{abstract}

Keywords: Glutamine; Food Additive Product; Liquid Chromatography

\section{Introduction}

Glutamine is a multifaceted amino acid that plays key roles in many metabolic pathways and also fulfils essential signaling functions. Although classified as non-essential, recent evidence suggests that glutamine is a conditionally essential amino acid in several physiological situations [1]. Glutamine might be a good nitrogen source in the mammals diet, since higher organisms are not capable to synthesize nitrogen-containing organic compounds from inorganic salts [2]. It has multiple physiological roles and functions: a precursor of nucleic acids, amino sugars, and proteins, an important nitrogen transporter, and a carrier of ammonia. It serves as a primary fuel source for rapidly dividing cells such as enterocytes and lymphocytes and as a prime source or energy for small intestine mucosa cells [3]. The chemical structure of glutamine is represented in Figure 1.

This amino acid may become essential under conditions of catabolic disease states such as sepsis, trauma, major surgery, burns, and uncontrolled diabetes [4]. Thus, during events of stress, the requirement for glutamine may be greater than the ability of the body to produce it, and ex-

${ }^{*}$ Corresponding author. ogenous supplementation may be required. These observations serve as the rationale for inclusion of glutamine in nutritional products formulated for patients under conditions of metabolic stress or malabsorptive disorders [3].

The literature describe HPLC method for the quantitative analysis of glutamine, glucose, lactate and alanine on suspended mammalian cell reactors, using isocratic elution of a mobile phase constituted of $5 \mathrm{mM} \mathrm{Ca}\left(\mathrm{NO}_{3}\right)_{2}$ (pH 5.5) [5]. A reversed-phase liquid chromatography method (RP-LC) was described for the determination of glutamine and $\mathrm{N}$-acetylglutamine in aqueous solution and in a liquid nutritional product, using isocratic elution at a flow-rate of $1 \mathrm{~mL} / \mathrm{min}$ [3]. Moreover, HPLC method<smiles>CNCCCC(N)=O</smiles>

Figure 1. Chemical structure of glutamine. 
was validated with electrochemical detection for glutamate, glutamine and GABA determination in brain homogenates. The protocol was based on a precolumn derivatization of amino acids with o-phthalaldehyde and sodium sulfite, a separation through a C18 column and an isocratic elution [6].

Although there are recently developed methods of amino acid analyses, such as gas chromatography, which are faster and less expensive, ion exchange method of amino acid analysis is the best despite its being expensive, and will continue to be used for this purpose for years to come because of its reproducibility, recently achieved better speed, and complete automation [7].

The ion exchange takes place on resin, consisting of small spherical beads of polystyrene, reacted with divinylbenzene to achieve the required degrees of cross linkage between the two polymerised chains of styrene, and sulphonated to provide an electrical charge. The chromatographic column is filled with resins of negative charge, and the amino acids are put on the column at a low $\mathrm{pH}$ value (about 2.0), hence all of them bear a positive charge. In these conditions all of the amino acids will link to the resin, no chromatographic division will occur, and the amino acids are waiting at the beginning of the column for a change in conditions. If the $\mathrm{pH}$ and the ionic strength of the elution buffers increase, the isoelectric point of the amino acids will be reached, and the attraction of the ions towards the resin diminishes and so the amino acids will be eluted from the column. The conditions of the separation of the amino acids can be modifed in a way that the isoelectric points, for all amino acids, are to be reached at various times [8].

There is a limitation in amino acids analysis concerning sensitive and/or selective detection after chromatographic run. These substances often lack from a suitable chromophore, fluorophore or electrophore and have to be detected by the UV-absorption within the wavelength range from 205 to $230 \mathrm{~nm}$. This range, however, is very unspecific because a lot of substances show UV-absorption therein $[9,10]$. This detection problem could be solved by derivatization procedures which allow transforming amino acids onto detectable forms. Many publications have reported the use of derivatization methods for improving a protein's detectability [11].

Ion-exchange chromatography followed by post-column derivatization has been a method of choice for amino acid analysis for many years. In the post-column derivatization, the analytes are reacted with derivatizing reagent after their HPLC separation and before they reach the detector [9]. The advantage of this process is the previous separation of reaction interfering analytes. This constitutes an advantage when dealing with unknown, complex mixtures [12]. Furthermore, the amino acids are directly injected into the chromatographic column, which avoids the decomposition of derivates before injection or inside the chromatographic system. In this approach, the resolution of the derivates and quantitativity of the reactions is not needed [13]. Ninhydrin is the most frequently applied reagent for residue derivatization in the postcolumn approach. It is still considered the standard method of the technology. The advantages of the method are that it is robust, reliable, and reproducible and it can detect a large number of amino acids and homologs [12]. Ninhydrin reacts to decarboxylate the amino acids, and yield an intensively colored purple blue product having absorption maximum at $570 \mathrm{~nm}$. The reaction of ninhydrin with amino acid is very sensitive and is represented in Figure 2 [7].

Validated procedures to evaluation of glutamine in food additive products were not found in the literature. Thus, the aim of this study was to validate IEC method for analysis of this important amino acid. The method uses a mobile phase without organic solvents, UV-visible detection and does not require complicated sample preparation. The availability of this rapid and selective method will be very useful for determination of glutamine. The method was validated in accordance with the specifications of the International Conference on Harmonization [14].

\section{Material and Methods}

\subsection{Chemicals and Reagents}

The glutamine reference substance and glutamic acid reference substance were supplied by Sigma-Aldrich (St Louis, Missouri, USA). Batches of glutamine in food additive products were obtained from production process of Ajinomoto (São Paulo, Brazil). Analytical grade sodium eluant, $\mathrm{pH} 3.15$, with $5 \%$ sulfolane, sodium eluant, $\mathrm{pH}$ 7.40 , sodium column regenerant and ninhydrin reagent were acquired from Pickering Laboratories (Mountain View, California, USA). All chemicals used were special analytical grade. For all of the analyses, ultrapure water was purified using an Elix 3 coupled to a Milli-Q Gradient A10 system (Millipore, Bedford, MA, USA).

\subsection{Apparatus and Chromatographic Conditions}

An Agilent 1100 LC system (Agilent Technologies, Waldbronn, Germany) equipped with quaternary pump, colu$\mathrm{mn}$ oven, refrigerated autosampler and UV-Vis detector was used. The LC system was coupled with Pickering Laboratories PCX 5200 post-column derivatization system (Mountain View, California, USA).

\subsection{Ion-Exchange Chromatography (IEC)}

The experiments were performed on a high efficiency sodium cation-exchange Pickering Laboratories column $(4.0 \times 150 \mathrm{~mm})$. A security guard holder was used to 


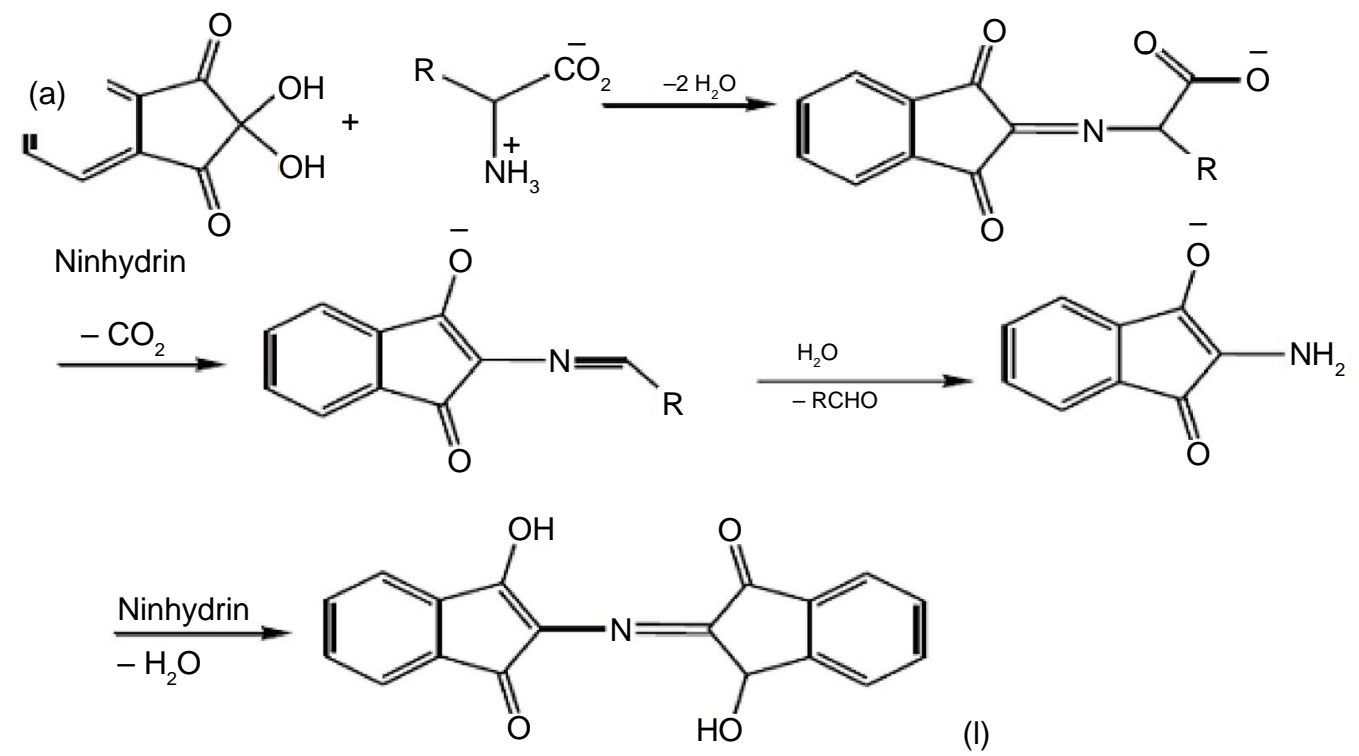

Purple colored product

Figure 2. Reactions of ninhydrin with amino acid (Khan and Faiz, 2008).

protect the analytical column. The Agilent LC system was operated using a mobile phase consisted sodium eluant, $\mathrm{pH} 3.15$, with 5\% sulfolane, sodium eluant, $\mathrm{pH} 7.40$, sodium column regenerant and using UV-Vis detection at $570 \mathrm{~nm}$. The gradient program was implemented as follows: time $=0 \mathrm{~min}, \mathrm{~A}: \mathrm{B}: \mathrm{C}(100: 0: 0)$; time $=12 \mathrm{~min}$, $\mathrm{A}: \mathrm{B}: \mathrm{C}(100: 0: 0)$; time $=34 \mathrm{~min}, \mathrm{~A}: \mathrm{B}: \mathrm{C}(0: 100: 0)$; time $=$ $53 \mathrm{~min}, \mathrm{~A}: \mathrm{B}: \mathrm{C}(0: 100: 0)$; time $=53.1 \mathrm{~min}, \mathrm{~A}: \mathrm{B}: \mathrm{C}$ $(0: 0: 100) ;$ time $=55 \mathrm{~min}, \mathrm{~A}: \mathrm{B}: \mathrm{C}(0: 0: 100) ;$ time $=55.1$ min, A:B:C (100:0:0), maintaing this proportion until time $=67 \mathrm{~min}$. The flow-rate of the mobile phase was 0.4 $\mathrm{mL} / \mathrm{min}$, and the flow-rate of the derivatizating reagent was $0.3 \mathrm{~mL} / \mathrm{min}$. The column temperature was set at $48^{\circ} \mathrm{C}$ and the post column reaction equipment was kept at $130^{\circ} \mathrm{C}$ temperature. The temperature of the auto-sampler was kept at $5^{\circ} \mathrm{C}$ and the injection volume was $10 \mu \mathrm{L}$ for both standard and samples.

\subsection{Preparation of Samples and Standard Solutions}

Working standard and sample solutions of glutamine were prepared daily by diluting the standard for glutamine and the samples of food additive products in ultrapure water, to a final concentration of $25 \mu \mathrm{g} / \mathrm{mL}$.

\section{Experimental}

\subsection{Validation of the IEC Method}

Once the chromatographic and the experimental conditions were optimized, the method was validated by the determination of the following parameters: specificity, linearity, precision, accuracy, limit of detection and limit of quan- titation following the International Conference on Harmonisation guidelines [14].

\subsubsection{Specificity}

Specificity of the method towards the amino acid was established through the determination of the resolution between peaks of glutamine and glutamic acid reference substances. The solution of two amino acids was prepared by mixture of equal volumes of the glutamine $(25 \mu \mathrm{g} / \mathrm{mL})$ and glutamic acid $(25 \mu \mathrm{g} / \mathrm{mL})$ solutions.

\subsubsection{Linearity}

Linearity was determined by constructing an analytical curve with five reference substance concentrations of the glutamine in the range of $4-50 \mu \mathrm{g} / \mathrm{mL}$ prepared in ultrapure water. Before injection of the solutions, the column was equilibrated for at least $20 \mathrm{~min}$ with the mobile phase flowing through the system. Three replicate of $10 \mu \mathrm{L}$ injections of the reference solutions were made to verify the repeatability of the detector response. The peak areas of the chromatograms were plotted against the respective concentrations of glutamine reference substance to obtain the analytical curve. The results were subjected to regression analysis by the least squares method to calculate calibration equation and determination coefficient.

\subsubsection{Precision}

The precision of the method was determined by repeatability (intra-day) and intermediate precision (inter-day). Repeatability was examined by three evaluations of the three concentrations of glutamine standard, on the same 
day, under the same experimental conditions. The intermediate precision of the method was assessed by carrying out the analysis on three different days (inter-days). Intra-and inter-day precision were expressed as relative standard deviation (RSD).

\subsubsection{Accuracy}

To confirm the accuracy of the method, recovery was determined at three concentrations, by adding known amounts of the reference substance at the samples of production process, to obtain solutions at concentrations of 4,25 and $50 \mu \mathrm{g} / \mathrm{mL}$, equivalent to $16 \%, 100 \%$ and $200 \%$ of the nominal analytical concentration, respectively. The accuracy was calculated as the percentage of the reference substance recovered from the samples.

\subsubsection{Limits of Detection and Quantitation}

The limits were defined by the determination of the signalto-noise ratio by comparison of measured signals from samples with known low concentrations of analyte with those of blank samples and by establishing the minimum concentration at which the analyte was reliably detected, for the limit of detection (signal-to-noise ratio is 3:1), and quantified with acceptable accuracy and precision, for the limit of quantitation (signal-to-noise ratio is 10:1).

\section{Results and Discussion}

\subsection{Optimization of Chromatographic Conditions}

To obtain the best chromatographic conditions, the mobile phases were optimized to provide appropriate selectivity and sensitivity. The use of a gradient elution resulted in better sensitivity, improving the peak symmetry with the retention time also suitable for the separation of glutamic acid and glutamine. The optimized conditions of the LC method were validated for the analysis of glutamine in food additive products.

\subsection{Method Validation}

The results of the method validation are shown in Table 1.

\subsubsection{Specificity}

The analysis of the glutamine standard showed the specificity of the analytical method. The resolution of glutamic acid and glutamine peaks was 5.31 and the tailing factor of glutamine peak was 0.99 . The symmetrical peak corresponding to glutamine, with the retention time of 10.1 min were shown in Figure 3, demonstrating also that the proposed method is able to separate glutamic acid and glutamine.

\subsubsection{Linearity}

The analytical curve constructed for glutamine was found to be linear in the $4-50 \mu \mathrm{g} / \mathrm{mL}$ range. The value of the
Table 1. Validation results of IEC for glutamine in food additive products.

\begin{tabular}{cccc}
\hline Parameters & \multicolumn{2}{c}{ Results } \\
\hline \multirow{2}{*}{ Specificity } & & \multicolumn{3}{c}{ Resolution $5.31^{a}$} \\
& & \multicolumn{3}{c}{ Tailing factor 0.99 } \\
Linearity & & \multicolumn{2}{c}{$r^{2}=0.9999$} \\
& & $4 \mu \mathrm{g} / \mathrm{mL}$ & $(0.72 \%)^{\mathrm{b}}$ \\
& Repeatability & $25 \mu \mathrm{g} / \mathrm{mL}$ & $(2.61 \%)^{\mathrm{b}}$ \\
Precision & (intra-day) & $50 \mu \mathrm{g} / \mathrm{mL}$ & $(0.65 \%)^{\mathrm{b}}$ \\
& & $4 \mu \mathrm{g} / \mathrm{mL}$ & $(1.82 \%)^{\mathrm{b}}$ \\
& Intermediate & $25 \mu \mathrm{g} / \mathrm{mL}$ & $(2.56 \%)^{\mathrm{b}}$ \\
& (inter-day) & $50 \mu \mathrm{g} / \mathrm{mL}$ & $(4.63 \%)^{\mathrm{b}}$ \\
& & $4 \mu \mathrm{g} / \mathrm{mL}$ & $(111.83 \%)^{\mathrm{c}}$ \\
Accuracy & & $25 \mu \mathrm{g} / \mathrm{mL}$ & $(93.29 \%)^{\mathrm{c}}$ \\
& & $50 \mu \mathrm{g} / \mathrm{mL}$ & $(94.21 \%)^{\mathrm{c}}$ \\
Limit of Detection & & \multicolumn{3}{c}{$0.11 \mu \mathrm{g} / \mathrm{mL}$} \\
Limit of Quantitation & & \multicolumn{3}{c}{$0.35 \mu \mathrm{g} / \mathrm{mL}$} \\
\hline
\end{tabular}

${ }^{\mathrm{a}}$ Resolution of glutamic acid and glutamine peaks; ${ }^{\mathrm{b}}$ Relative Standard Deviation; ${ }^{\mathrm{C}}$ Percentage of recovered glutamine.

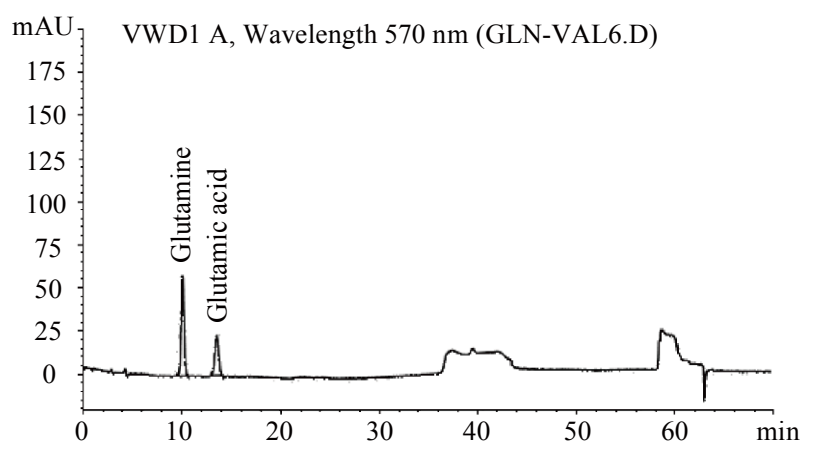

Figure 3. Representative IEC chromatograms of glutamic acid and glutamine.

determination coefficient calculated $\left(r^{2}=0.9999, y=\right.$ $72.97350 x-16.22441$, where, $x$ is concentration and $y$ is the peak absolute area) indicated the linearity of the analytical curve for the method.

\subsubsection{Precision}

The precision evaluated as the repeatability of the method was studied by calculating the relative standard deviation (RSD) for three determinations of the concentrations 4, 25 and $50 \mu \mathrm{g} / \mathrm{mL}$ performed on the same day and under the same experimental conditions. The RSD values obtained were $0.72 \%, 2.61 \%$ and $0.65 \%$, respectively.

The intermediate precision was assessed by calculating the relative standard deviation (RSD) for determinations of the three levels of concentration on three different days (inter-day). The RSD values obtained between days were $1.82 \%, 2.56 \%$ and $4.63 \%$, for samples 4,25 and 50 $\mu \mathrm{g} / \mathrm{mL}$, respectively.

\subsubsection{Accuracy}

The accuracy was calculated as the percentage of the drug 
recovered from three replicate determinations of three different solutions containing 4,25 and $50 \mu \mathrm{g} / \mathrm{mL}$, constituted of glutamine sample and standard (50:50). The absolute means obtained of recovered glutamine were $111.83 \%, 93.29 \%$ and $94.21 \%$, respectively, demonstrating that the method is accurate within the desired range.

\subsubsection{Limits of Detection and Quantitation}

The limit of detection and limit of quantitation determined were $0.11 \mu \mathrm{g} / \mathrm{mL}$ and $0.35 \mu \mathrm{g} / \mathrm{mL}$, respectively.

Based on the findings of the present work, it can be concluded that analysis via ion-exchange chromatography (IEC) followed by post-column derivatization method, is indeed a viable alternative for determining glutamine quality. This method can be useful in quality control during and after production of glutamine food additive products.

\section{Conclusion}

The results of the validation studies show that the IEC method is sensitive with a limit of quantitation of 0.35 $\mu \mathrm{g} / \mathrm{mL}$, accurate with a mean value of $99.78 \%$, and possesses significant linearity $\left(r^{2}=0.9999\right)$. The separation was achieved with the retention time of $10.1 \mathrm{~min}$, and the method has been successfully used for analysis of glutamine. Moreover, the validated physicochemical technique employed, offered a high degree of resolving power and selectivity and is suggested as an analytical alternative to improve the quality control of food additive products containing glutamine.

\section{Acknowledgements}

This work was supported by $\mathrm{CNPq}-\mathrm{Brazil}$ program and PACD-FCF-UNESP.

\section{REFERENCES}

[1] J. M Matés, J. A. Segura, J. A. Campos-Sandoval, C. Lobo, L. Alonso, F. J. Alonso and J. Márquez, "Glutamine Homeostasis and Mitochondrial Dynamics," The International Journal of Biochemistry \& Cell Biology, Vol. 41, No. 10, 2009, pp. 2051-2061.

doi:10.1016/j.biocel.2009.03.003

[2] U. Hellmann, I. Lüderwald, M. Neuhaüser and Z. Fresen, "Determination of N-acetyl-L-glutamine in Urine by HPLC," Fresenius' Journal of Analytical Chemistry, Vol. 325, No. 3, 1986, pp. 290-292. doi:10.1007/BF00498176

[3] M. K. Snowden, J. H. Baxter, M. Mamula Bergana, I. Reyzer and V. Pound, "Stability of N-Acetylglutamine and Glutamine in Aqueous Solution and in a Liquid Nutritional Product by an Improved HPLC Method," Jour- nal of Food Science, Vol. 67, No. 1, 2002, pp. 384-389. doi:10.1111/j.1365-2621.2002.tb11415.x

[4] J. M. Lacey and D. W. Wilmore, "Is Glutamine Conditionally Essential Amino Acid?" Nutrition Reviews, Vol. 48, No. 8, 1990, pp. 297-309. doi:10.1111/j.1753-4887.1990.tb02967.x

[5] E. Frave, P. Pugeaud and P. Péringer, "Automated HPLC Monitoring of Glucose, Glutamine, Lactate and Alanine on Suspended Mammalian Cell Reactors," Biotechnology Techniques, Vol. 4, No. 5, 1990, pp. 315-320.

[6] A. A. Monge-Acuña and J. Fornaguera-Trías, "A High Performance Liquid Chromatography Method with Electrochemical Detection of Gamma-Aminobutyric Acid, Glutamate and Glutamine in Rat Brain Homogenates," Journal of Neuroscience Methods, Vol. 183, No. 2, 2009, pp. 176-181. doi:10.1016/j.jneumeth.2009.06.042

[7] A. S. Khan and F. Faiz, "Amino Acid Analysis Using Ion Exchange Resins," Journal of Natural Sciences and Mathematics, Vol. 48, No. 1-2, 2008, pp. 1-17.

[8] J. Csapó, Cs. Albert, K. Lóki and Zs. Csapó-Kiss, "Separation and Determination of the Amino Acids by Ion Exchange Column Chromatography Applying Postcolumn Derivatization," Acta Universitatis Sapientiae Alimentaria, Vol. 1, 2008, pp. 5-29.

[9] M. Koller and H. Eckert, "Derivatization of Peptides for Their Determination by Chromatographic Methods," Analytica Chimica Acta, Vol. 352, No. 1-3, 1997, pp. 3159. doi:10.1016/S0003-2670(97)00321-8

[10] K. M. De Antonis, P. R. Brown and S. A. Cohen, "High-Performance Liquid Chromatographic Analysis of Synthetic Peptides Using Derivatization with 6-Aminoquinolyl- $N$-Hydroxysuccinimidyl Carbamate," Analytical Biochemistry, Vol. 223, No. 2, 1994, pp. 191-197. doi:10.1006/abio.1994.1572

[11] C. Sun, J. Yang, L. Li, X. Wu, Y. Liu and S. Liu, "Advances in the Study of Luminescence Probes for Proteins," Journal of Chromatography B, Vol. 803, No. 2, 2004, pp. 173-190. doi:10.1016/j.jchromb.2003.12.039

[12] M. Fountoulakis and H. Lahm, "Hydrolysis and Amino Acid Composition Analysis of Proteins," Journal of Chromatography A, Vol. 826, No. 2, 1998, pp. 109-134. doi:10.1016/S0021-9673(98)00721-3

[13] S. López-Grío, J. R. Torres-Lapasió, J. J Baeza-Baeza and M. C. García-Alvarez-Coque, "Micellar Liquid Chromatographic Separation of Amino Acids Using Preand PostColumn O-phthalaldehyde/N-acetylcysteine Derivatization," Analytica Chimica Acta, Vol. 418, No. 2, 2000, pp. 153-165. doi:10.1016/S0003-2670(00)00965-X

[14] ICH Q2(R1), "Validation of Analytical Procedures: Text and Methodology," International Conference on Harmonization of Technical Requirements for the Registration of Pharmaceutical for Human Use, Geneva, Switzerland, 2005. 